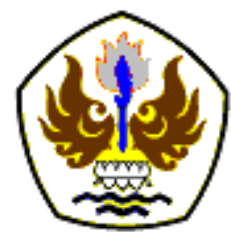

INFOMATEK

Volume 22 Nomor 2 Desember 2020

\title{
MERANCANG MODEL PENJADWALAN KONSTRUKSI MULTI BENDING DENGAN MEMPERTIMBANGKAN POLA ALIRAN PROSES JOB SHOP UNTUK MEMINIMUMKAN MAKESPAN
}

\author{
Rinto Yusriski ${ }^{\star}$, Ragil Pardiyono, Sinta Rahmawati, Lia Nur Atika \\ Universitas Jenderal Achmad Yani
}

\begin{abstract}
Abstrak: PT XYZ merupakan salah satu perusahaan manufaktur yang bergerak di bidang mebel seperti meja, rak dan kursi. Karakteristik pekerjaan yang diproses perusahaan adalah terdapat sejumlah pekerjaan yang harus dikerjakan pada mesin-mesin dengan routing yang berbeda-beda (memiliki aliran proses job shop) dan setiap pekerjaan terdiri atas satu atau lebih unit permintaan. Hasil studi awal menunjukkan bahwa terdapat masalah pada Departemen produksi bagian konstruksi multi bending yaitu tidak tercapainya target produksi harian (tercapai sebesar 77\%). Berdasarkan hasil pengecekan kapasitas menunjukkan bahwa kapasitas tersedia sebesar 22.080 menit, sementara waktu yang diperlukan adalah 5.472 menit. Dengan demikian, target produksi seharusnya dapat selesai pada waktu yang telah ditetapkan oleh perusahaan. Studi awal menyimpulkan bahwa metoda penjadwalan perusahaan perlu diperbaiki. Perusahaan mengadopsi teknik penjadwalan dengan aturan prioritas First-Come-First-Serve (FCFS), yaitu prioritas pengerjaan job diurutkan berdasarkan saat kedatangan job ke lantai produksi. Analisa awal menunjukkan bahwa keterlambatan ini disebabkan oleh pengiriman pekerjaan dari suatu mesin ke mesin yang lain yang dilakukan setelah seluruh komponen pekerjaan tersebut diselesaikan. Hal ini mengakibatkan makespan yang panjang sehingga beberapa pekerjaan selesai melampaui saat tenggat (due date). Pada sistem nyata diketahui bahwa stasiun kerja memiliki jumlah mesin lebih dari satu sehingga memungkinkan job untuk dijadwalkan pada mesin-mesin tersebut secera paralel. Selain itu, komponen-komponen dari job yang telah selesai bisa saja dikirimkan pada mesin selanjutnya (operation overlapping) sesuai routing tanpa harus menunggu seluruh komponen selesai. Hal ini membutuhkan penentuan besar ukuran lot yang harus ditransfer antar mesin. Penelitian ini mengusulkan metode penjadwalan dengan menggunakan prioritas Shortest Processing Time (SPT) yang digkombinasikan dengan teknik lot splitting. Asumsi yang digunakan adalah seluruh job sudah tersedia dari saat $t=0$. Hasil dari penjadwalan usulan ini mempunyai hasil yang lebih baik dalam mengurangi makespan sebesar 20,7\% dan meningkatkan utilitas mesin sebesar $8 \%$.
\end{abstract}

Kata kunci: Job Shop, Makespan, Shortest Processing Time, Lot Splitting

\section{PENDAHULUAN}

PT XYZ merupakan perusahaan manufaktur dengan produk yang dihasilkan berbagai jenis kursi, meja, rak, dan tempat tidur rumah

*) yusarisaki@gmail.com

Pertama diterima: 12 November 2020

Direvisi: 20 November 2020

Disetujui untuk publikasi: 25 November 2020 sakit. Kursi merupakan salah satu produk yang paling banyak diminati karena kursi memiliki banyak jenis dengan desain yang berbeda. Strategi respon pasar yang ditetapkan adalah Make To Order dan Make To Stock. Strategi ini digunakan untuk memenuhi keinginan konsumen yang tidak 
menentu berdasarkan jumlah dan jenis produk yang dipesan. Pada departemen produksi terdapat tiga bagian umum yaitu bagian konstruksi, bagian pelapisan dan bagian perakitan. Bagian konstruksi bertugas menghasilkan komponen dari bahan baku pipa logam melalui proses bending (pembengkokan) dan welding (pengelasan). Bagian pelapisan bertugas melakukan proses pelapisan terhadap komponen dengan tujuan melindungi dari terjadinya korosi atau karat. Bagian perakitan bertugas merakit beberapa komponen menjadi produk jadi.

Fokus penelitian ini adalah bagian konstruksi multi bending. Pada bagian ini terdapat beberapa proses, proses bending (pembengkokan), proses sweging (pembentukan ujung pipa, lebih lebar), proses knocking (pembentukan permukaan pipa menonjol ke arah dalam), proses shrinking (pembentukan ujung pipa menjadi lebih kecil), proses pressing (penekanan), proses forming (pembentukan) dan proses piercing (pelubangan pipa dengan cara press). Bagian konstruksi multi bending memiliki delapan operator dan 33 mesin dengan jenis dan fungsi yang sama maupun berbeda. Setiap mesin memiliki waktu set-up yang berbeda antara 30-180 menit per mesin. Alur proses produksi di konstruksi multi bending memiliki aliran job shop.
Proses penjadwalan pekerjaan di perusahaan menggunakan metode prioritas First-Come-First-Serve (FCFS). Menurut Heizer dan Render [1], FCFS memprioritaskan pengerjaan job yang datang lebih awal untuk dikerjakan lebih dulu. Data pada Bulan Juni 2019 menunjukkan bahwa penggunaan teknik penjadwalan ini menghasilkan pencapaian target produksi sebesar $77 \%$. Kondisi ini mengakibatkan terjadi keterlambatan dalam pengiriman barang ke konsumen. Berdasarkan hasil pengecekan kapasitas menunjukkan bahwa kapasitas tersedia sebesar 22.080 menit, sementara waktu yang diperlukan adalah 5.472 menit. Dengan demikian seharusnya target produksi dapat selesai pada waktu yang telah ditetapkan oleh perusahaan. Keterlambatan yang terjadi diduga akibat dari metode penjadwalan yang diterapkan perusahaan.

Masalah yang dibahas pada penelitian ini adalah merancang metode penjadwalan usulan pada bagian konstruksi multi bending yang mempertimbangkan pola aliran proses job shop. Kriteria keberhasilan metode usulan akan diukur dengan meminimumkan makespan. Makespan merupakan waktu rentang pembuatan produk atau total waktu yang dibutuhkan untuk menyelesaikan seluruh job (Puspawardhani dan Yusriski [2]). 


\section{METODOLOGI}

Kondisi sistem produksi pada bagian konstruksi multi bending memiliki pola aliran proses job shop dengan mesin yang disusun gabungan seri paralel. Sistem penjadwalan pada bagian konstruksi multi bending ini adalah sistem penjadwalan batch. Menurut Baker [3], Penjadwalan (scheduling) didefinisikan sebagai proses pengalokasian sumber untuk melaksanakan sekumpulan tugas dalam jangka waktu tertentu. Batch adalah sejumlah job yang dikelompokkan untuk diproses pada suatu mesin (Condotta et. al. [4]).

Model penjadwalan usulan untuk bagian konstruksi multi bending adalah dengan penjadwalan yang menggunakan lot splitting. Lot splitting Menurut Yusriski dan Halim [5] adalah proses menyeimbangkan jumlah ukuran batch dalam satu work center, dimana dalam satu work center terdapat jumlah mesin lebih dari sama dengan satu $\left(Q_{j}\right)$. Variabel yang mempengaruhi $Q_{j}$ diantaranya jumlah mesin yang sama $(m)$, demand setiap produk $(D)$, waktu proses produksi di mesin [i] nama_job $\left.[\mathrm{k}]\left(t_{i j[k]}\right]\right)$, waktu saat mulai proses produksi di mesin $[i] \mathrm{ke}-\mathrm{j}\left(S_{i j[k]}\right)$ dan total waktu saat mulai proses produksi di mesin [i] $\left(\sum S_{i m[k]}\right)$. Pendekatan ini dinamakan lot splitting karena sejumlah job/komponen dibagi secara seimbang jumlah ukuran batch dalam satu work center. Dengan pembagian yang rata akan meminimalisir makespan, sehingga model ini cocok untuk karakteristik permasalahan ini yang pola aliran prosesnya job shop dengan jadwal produksi job/komponen setiap harinya berbeda-beda. (Low et. Al. [6])

\section{ANALISIS DAN PEMBAHASAN}

Konstruksi multi bending pada dasarnya memiliki pola aliran proses job shop. Menurut Baker dan Trietsch [7] pola aliran job shop yaitu setiap job dapat melalui urutan proses yang berbeda- beda dengan mesin yang berbeda pula. Model penjadwalan usulan untuk bagian konstruksi multi bending adalah dengan penjadwalan yang menggunakan lot splitting. Proses penjadwalan lot splitting dipengaruhi oleh jumlah mesin yang sama, demand setiap produk, waktu proses produk, waktu mulai proses produk di setiap mesin dan total waktu saat mulai proses produksi di mesin.

\subsection{Penjadwalan Dengan Lot Splitting}

Menggunakan algoritma lot splitting untuk menjadwalkan job di konstruksi multi bending sebagai berikut:

1. Langkah 0: Tentukan jumlah job (jj), lanjutkan ke Langkah 1.

2. Langkah 1: Tentukan nama_job [k], dan demand dari setiap job (D) sebanyak jumlah job (j)), lanjutkan ke Langkah 2.

3. Langkah 2: Lakukan pengurutan 
nama_job [k] dari $\mathrm{D}$ terkecil sampai dengan $D$ terbesar, lanjutkan ke langkah 3. Langkah 3: Tentukan n; nama_job [k], demand dari setiap job (D) jumlah_operasi (jo), lanjutkan ke langkah 4.

4. Langkah 4: Tentukan nama_mesin [i], jumlah mesin yang sama $(m)$, waktu proses produksi di mesin [i] ke-j, nama_job [k] $\left(t_{i j[k]}\right)$, dan waktu saat mulai proses produksi di mesin [i] kej, nama_job [k] $\left(S_{\mathrm{ij} j \mathrm{k}]}\right)$. Lanjutkan ke langkah 5 .

5. Langkah 5:

a. Jika nama_mesin [i] mengandung kata "double", lanjutkan ke Langkah 6.

b. Jika nama_mesin [i] tidak mengandung kata "double", lanjutkan ke Langkah 7. Karena nama_mesin [i] tidak mengandung kata "double", lanjutkan ke Langkah 7.

6. Langkah 7:

Tentukan $\sum S_{\mathrm{i} m[\mathrm{k}]}=S_{\mathrm{ij}[\mathrm{k}]}+S_{\mathrm{ij}[\mathrm{k}]}+\quad+S_{\mathrm{ij}[\mathrm{k}]}$, lanjutkan ke Langkah 8.

7. Langkah 8: Tentukan jumlah quantity mesin ke-j $\left(Q_{\mathrm{j}}\right)$, dengan rumus lanjut langkah 9

8. Langkah 9

Tentukan waktu proses yang diperlukan untuk suatu batch menggunakan $Q_{j}$ yang didapatkan dari langkah 8 dengan rumus $L_{\mathrm{ij}[\mathrm{k}]}=Q_{\mathbf{j}} * t_{\mathrm{ij}[\mathrm{k}]}$, lanjutkan ke Langkah 10.

9. Langkah 10:

Tentukan waktu saat mulai yang digunakan untuk job selanjutnya $\left(\oint_{i[k+1]}\right)$, menggunakan $L_{\mathrm{ij}[\mathrm{k}]}$ yang didapatkan dari Langkah 9 dengan rumus $S_{\mathrm{ij}[\mathrm{k}+1]}=S_{\mathrm{ij}[\mathrm{k}]}+L_{\mathrm{ij}[\mathrm{k}]}$, lanjutkan ke Langkah 11.

10. Langkah 11:

Lakukan pengulangan Langkah 8 sampai dengan Langkah 10 sesuai dengan jumlah mesin yang sama $(\mathrm{m})$, lanjutkan ke Langkah 12.

Terdapat 4 unit mesin Pine Bender Chiwork, sedangkan perhitungan baru dilakukan pada 1 unit mesin Pine Bender Chiwork, maka akan dilakukan pengulangan perhitungan sebanyak $3 x$.

11. Langkah 12:

Tampilkan hasil perhitungan dengan format nama_job [k], nama_mesin [i], jumlah mesin $(m)$, waktu saat mulai proses produksi di mesin [i] ke-j $\left(S_{\mathrm{ij}[\mathrm{k}]}\right)$, quantity mesin ke-j $\left(Q_{\mathrm{j}}\right)$, waktu proses yang diperlukan untuk suatu batch, dengan $Q_{j}$ yang didapatkan $\left(L_{\mathrm{ij}[\mathrm{k}]}\right)$, dan waktu saat mulai yang digunakan untuk job selanjutnya $\left(S_{i j[k+1]}\right)$. Lanjutkan ke Langkah 13.

12. Langkah 13: 
Lakukan pengulangan Langkah 4 sampai dengan Langkah 12 sesuai dengan jumlah_operasi (jo), lanjutkan ke Langkah 14.

Karena, terdapat dua proses operasi untuk memproduksi KB Cozy sedangkan perhitungan telah dilakukan pada satu operasi, maka terdapat satu operasi yang belum dijadwalkan.

13. Langkah 14:

Tampilkan gantt chart dari semua job yang telah dijadwalkan, lanjutkan ke Langkah 15.

14. Langkah 15:

Lakukan pengulangan Langkah 3 sampai dengan Langkah 14 sesuai dengan jumlah job (jj), lanjutkan ke Langkah 16.

15. Langkah 16:

Iterasi selesai.

Berdasarkan hasil penelitian yang dilakukan mengenai penjadwalan batch pada hybrid job shop dengan metode lot splitting di bagian konstruksi multi bending PT. XYZ, maka diperoleh hasil sebagai berikut:

1. urutan komponen yang dihasilkan dari penjadwalan usulan adalah komponen KB Cozy, Leg Lotus R, Leg Lotus L, Seat Samm, KD Cozy R, KD Cozy L, Leg Flora SN Lower, Leg Flora SN Upper, Back Taro dan KB Flora $\mathrm{H}$;
2. jadwal produksi di konstruksi multi bending; a. Komponen KB Cozy

Tabel 1. Jadwal produksi komponen KB Cozy

\begin{tabular}{|c|c|c|c|c|}
\hline \multirow{2}{*}{$\begin{array}{c}\text { Mesin } \\
\text { ke }\end{array}$} & \multicolumn{2}{|c|}{$\begin{array}{c}\text { Operasi ke-1 } \\
\text { Mesin Pine Bender } \\
\text { Chiwork }\end{array}$} & \multicolumn{2}{c|}{$\begin{array}{c}\text { Operasi ke-2 } \\
\text { Mesin Press 40 Ton }\end{array}$} \\
\cline { 2 - 5 } & $\begin{array}{c}\text { Saat } \\
\text { Mulai }\end{array}$ & $\begin{array}{c}\text { Saat } \\
\text { Selesai }\end{array}$ & $\begin{array}{c}\text { Saat } \\
\text { Mulai }\end{array}$ & $\begin{array}{c}\text { Saat } \\
\text { Selesai }\end{array}$ \\
\hline Mesin 1 & menit 0 & menit 33 & menit 33 & menit 59 \\
\hline Mesin 2 & menit 0 & menit 33 & menit 33 & menit 58 \\
\hline Mesin 3 & menit 0 & menit 33 & menit 33 & menit 58 \\
\hline Mesin 4 & menit 0 & menit 32 & & \\
\hline
\end{tabular}

b. Komponen Leg Lotus $\mathrm{R}$

Tabel 2. Jadwal produksi komponen Leg Lotus $R$

\begin{tabular}{|c|c|c|c|c|}
\hline \multirow{2}{*}{$\begin{array}{c}\text { Mesin } \\
\text { ke }\end{array}$} & \multicolumn{2}{|c|}{$\begin{array}{c}\text { Operasi ke-1 } \\
\text { Mesin CNC Bending }\end{array}$} & \multicolumn{2}{|c|}{$\begin{array}{c}\text { Operasi ke-2 } \\
\text { Mesin Press } 40 \text { Ton }\end{array}$} \\
\hline & $\begin{array}{l}\text { Saat } \\
\text { Mulai }\end{array}$ & $\begin{array}{c}\text { Saat } \\
\text { Selesai }\end{array}$ & $\begin{array}{l}\text { Saat } \\
\text { Mulai }\end{array}$ & $\begin{array}{c}\text { Saat } \\
\text { Selesai }\end{array}$ \\
\hline Mesin 1 & menit 0 & menit 90 & menit 90 & Menit 140 \\
\hline Mesin 2 & menit 0 & menit 89 & menit 90 & menit 140 \\
\hline Mesin 3 & & & menit 90 & menit 140 \\
\hline \multirow[b]{2}{*}{ Mesin ke } & \multicolumn{2}{|c|}{$\begin{array}{c}\text { Operasi ke-3 } \\
\text { Mesin Pine Bender } \\
\text { Chiwork }\end{array}$} & \multicolumn{2}{|c|}{$\begin{array}{c}\text { Operasi ke-4 } \\
\text { Mesin Press } 25 \text { Ton }\end{array}$} \\
\hline & $\begin{array}{l}\text { Saat } \\
\text { Mulai }\end{array}$ & $\begin{array}{c}\text { Saat } \\
\text { Selesai }\end{array}$ & $\begin{array}{l}\text { Saat } \\
\text { Mulai }\end{array}$ & $\begin{array}{c}\text { Saat } \\
\text { Selesai }\end{array}$ \\
\hline Mesin 1 & menit 141 & menit 164 & menit 164 & menit 201 \\
\hline Mesin 2 & menit 141 & menit 164 & menit 164 & menit 200 \\
\hline Mesin 3 & menit 141 & menit 164 & menit 164 & menit 200 \\
\hline Mesin 4 & menit 141 & menit 164 & & \\
\hline \multirow{2}{*}{$\begin{array}{c}\text { Mesin } \\
\text { ke }\end{array}$} & \multicolumn{2}{|c|}{$\begin{array}{c}\text { Operasi ke-5 } \\
\text { Mesin Press } 16 \text { Ton }\end{array}$} & \multicolumn{2}{|c|}{$\begin{array}{c}\text { Operasi ke-6 } \\
\text { Mesin Press } 16 \text { Ton }\end{array}$} \\
\hline & $\begin{array}{l}\text { Saat } \\
\text { Mulai }\end{array}$ & $\begin{array}{c}\text { Saat } \\
\text { Selesai }\end{array}$ & $\begin{array}{l}\text { Saat } \\
\text { Mulai }\end{array}$ & $\begin{array}{c}\text { Saat } \\
\text { Selesai }\end{array}$ \\
\hline Mesin 1 & menit 201 & menit 213 & menit 213 & menit 226 \\
\hline Mesin 2 & menit 201 & menit 213 & menit 213 & menit 226 \\
\hline Mesin 3 & menit 201 & menit 213 & menit 213 & menit 226 \\
\hline Mesin 4 & menit 201 & menit 213 & menit 213 & menit 226 \\
\hline Mesin 5 & menit 201 & menit 213 & menit 213 & menit 226 \\
\hline
\end{tabular}




\section{c. Komponen Leg Lotus L}

Tabel 3. Jadwal produksi komponen Leg Lotus $\mathrm{L}$

\begin{tabular}{|c|c|c|c|c|}
\hline \multirow{2}{*}{$\begin{array}{l}\text { Mesin } \\
\text { ke }\end{array}$} & \multicolumn{2}{|c|}{$\begin{array}{c}\text { Operasi ke-1 } \\
\text { Mesin CNC Bending }\end{array}$} & \multicolumn{2}{|c|}{$\begin{array}{c}\text { Operasi ke-6 } \\
\text { Mesin Press } 25 \text { Ton }\end{array}$} \\
\hline & $\begin{array}{l}\text { Saat } \\
\text { Mulai }\end{array}$ & $\begin{array}{c}\text { Saat } \\
\text { Selesai }\end{array}$ & $\begin{array}{l}\text { Saat } \\
\text { Mulai }\end{array}$ & $\begin{array}{c}\text { Saat } \\
\text { Selesai }\end{array}$ \\
\hline Mesin 1 & menit 90 & menit 179 & menit 201 & menit 251 \\
\hline Mesin 2 & menit 89 & menit 179 & menit 200 & menit 251 \\
\hline Mesin 3 & & & menit 200 & menit 250 \\
\hline \multirow{2}{*}{$\begin{array}{l}\text { Mesin } \\
\text { ke }\end{array}$} & \multicolumn{2}{|c|}{$\begin{array}{c}\text { Operasi ke-3 } \\
\text { Mesin Pine Bender }\end{array}$} & \multicolumn{2}{|c|}{$\begin{array}{c}\text { Operasi ke-4 } \\
\text { Mesin Press } 25 \text { Ton }\end{array}$} \\
\hline & $\begin{array}{l}\text { Saat } \\
\text { Mulai }\end{array}$ & $\begin{array}{c}\text { Saat } \\
\text { Selesai }\end{array}$ & $\begin{array}{l}\text { Saat } \\
\text { Mulai }\end{array}$ & $\begin{array}{c}\text { Saat } \\
\text { Selesai }\end{array}$ \\
\hline Mesin 1 & menit 251 & menit 274 & menit 274 & menit 311 \\
\hline Mesin 2 & menit 251 & menit 274 & menit 274 & menit 310 \\
\hline Mesin 3 & menit 251 & menit 274 & menit 274 & menit 310 \\
\hline Mesin 4 & menit 251 & menit 274 & & \\
\hline \multirow[b]{2}{*}{$\begin{array}{l}\text { Mesin } \\
\text { ke }\end{array}$} & \multicolumn{2}{|c|}{$\begin{array}{c}\text { Operasi ke-5 } \\
\text { Mesin Press } 16 \text { Ton }\end{array}$} & \multicolumn{2}{|c|}{$\begin{array}{c}\text { Operasi ke-6 } \\
\text { Mesin Press } 16 \text { Ton }\end{array}$} \\
\hline & $\begin{array}{l}\text { Saat } \\
\text { Mulai }\end{array}$ & $\begin{array}{c}\text { Saat } \\
\text { Selesai }\end{array}$ & $\begin{array}{l}\text { Saat } \\
\text { Mulai }\end{array}$ & $\begin{array}{c}\text { Saat } \\
\text { Selesai }\end{array}$ \\
\hline Mesin 1 & menit 311 & menit 323 & menit 323 & menit 336 \\
\hline Mesin 2 & menit 311 & menit 323 & menit 323 & menit 336 \\
\hline Mesin 3 & menit 311 & menit 323 & menit 323 & menit 336 \\
\hline Mesin & \multicolumn{2}{|c|}{$\begin{array}{c}\text { Operasi ke-5 } \\
\text { Mesin Press } 16 \text { Ton }\end{array}$} & \multicolumn{2}{|c|}{$\begin{array}{c}\text { Operasi ke-6 } \\
\text { Mesin Press } 16 \text { Ton }\end{array}$} \\
\hline
\end{tabular}

\section{e. Komponen KD Cozy R}

Tabel 6. Jadwal produksi komponen KB Cozy R

\begin{tabular}{|c|c|c|c|c|c|c|}
\hline \multirow{2}{*}{ Mesin ke } & \multicolumn{2}{|c|}{$\begin{array}{c}\text { Operasi ke-1 } \\
\text { Mesin Shrinking }\end{array}$} & \multicolumn{2}{c|}{$\begin{array}{c}\text { Operasi ke-2 } \\
\text { Mesin Pine Bender Chiwork }\end{array}$} & \multicolumn{2}{c|}{$\begin{array}{c}\text { Mperasi ke-3 } \\
\text { Mesin Shrinking }\end{array}$} \\
\cline { 2 - 7 } & $\begin{array}{c}\text { Saat } \\
\text { Mulai }\end{array}$ & Saat Selesai & Saat Mulai & Saat Selesai & Saat Mulai & Saat Selesai \\
\hline Mesin 1 & menit 0 & menit 164 & menit 164 & menit 210 & menit 359 & menit 398 \\
\hline Mesin 2 & & & menit 164 & menit 210 & menit 359 & menit 398 \\
\hline Mesin 3 & & & menit 164 & menit 210 & menit 359 & menit 398 \\
\hline Mesin 4 & & menit 164 & menit 210 & & \\
\hline
\end{tabular}

\section{f. Komponen KD Cozy L}

\begin{tabular}{|c|c|c|c|c|}
\hline ke & $\begin{array}{c}\text { Saat } \\
\text { Mulai }\end{array}$ & $\begin{array}{c}\text { Saat } \\
\text { Selesai }\end{array}$ & $\begin{array}{c}\text { Saat } \\
\text { Mulai }\end{array}$ & $\begin{array}{c}\text { Saat } \\
\text { Selesai }\end{array}$ \\
\hline Mesin 4 & menit 311 & menit 323 & menit 323 & menit 336 \\
\hline Mesin 5 & menit 311 & menit 323 & menit 323 & menit 336 \\
\hline
\end{tabular}

\section{d. Komponen Seat Samm}

Tabel 5. Jadwal produksi komponen Seat Samm

\begin{tabular}{|c|c|c|c|c|}
\hline \multirow{2}{*}{$\begin{array}{l}\text { Mesin } \\
\text { ke }\end{array}$} & \multicolumn{2}{|c|}{$\begin{array}{c}\text { Operasi ke-1 } \\
\text { Mesin Double Side } \\
\text { Bending }\end{array}$} & \multicolumn{2}{|c|}{$\begin{array}{c}\text { Operasi ke-2 } \\
\text { Mesin Bulseom Welder }\end{array}$} \\
\hline & $\begin{array}{l}\text { Saat } \\
\text { Mulai }\end{array}$ & $\begin{array}{c}\text { Saat } \\
\text { Selesai }\end{array}$ & $\begin{array}{c}\text { Saat } \\
\text { Mulai }\end{array}$ & $\begin{array}{c}\text { Saat } \\
\text { Selesai }\end{array}$ \\
\hline Mesin 1 & menit 0 & menit 40 & menit 40 & menit 137 \\
\hline Mesin 2 & menit 0 & menit 40 & & \\
\hline \multirow[b]{2}{*}{$\begin{array}{l}\text { Mesin } \\
\text { ke }\end{array}$} & \multicolumn{2}{|c|}{$\begin{array}{c}\text { Operasi ke-3 } \\
\text { Mesin Press } 16 \text { Ton }\end{array}$} & \multicolumn{2}{|c|}{$\begin{array}{c}\text { Operasi ke-4 } \\
\text { Mesin Press } 25 \text { Ton }\end{array}$} \\
\hline & $\begin{array}{l}\text { Saat } \\
\text { Mulai }\end{array}$ & $\begin{array}{c}\text { Saat } \\
\text { Selesai }\end{array}$ & $\begin{array}{l}\text { Saat } \\
\text { Mulai }\end{array}$ & $\begin{array}{c}\text { Saat } \\
\text { Selesai }\end{array}$ \\
\hline Mesin 1 & menit 137 & menit 149 & menit 310 & menit 359 \\
\hline Mesin 2 & menit 137 & menit 149 & menit 311 & menit 359 \\
\hline Mesin 3 & menit 137 & menit 149 & menit 311 & menit 359 \\
\hline Mesin 4 & menit 137 & menit 149 & & \\
\hline Mesin 5 & menit 137 & menit 149 & & \\
\hline
\end{tabular}

Tabel 7. Jadwal produksi komponen KD Cozy L

\begin{tabular}{|c|c|c|c|c|c|c|}
\hline \multirow{2}{*}{ Mesin ke } & \multicolumn{2}{|c|}{$\begin{array}{c}\text { Operasi ke-1 } \\
\text { Mesin Shrinking }\end{array}$} & \multicolumn{2}{c|}{$\begin{array}{c}\text { Operasi ke-2 } \\
\text { Mesin Pine Bender Chiwork }\end{array}$} & \multicolumn{2}{c|}{$\begin{array}{c}\text { Operasi ke-3 } \\
\text { Mesin Press 25 Ton }\end{array}$} \\
\cline { 2 - 7 } & $\begin{array}{c}\text { Saat } \\
\text { Mulai }\end{array}$ & Saat Selesai & Saat Mulai & Saat Selesai & Saat Mulai & Saat Selesai \\
\hline Mesin 1 & menit 164 & menit 328 & menit 328 & menit 374 & menit 398 & menit 437 \\
\hline Mesin 2 & & & menit 328 & menit 374 & menit 398 & menit 437 \\
\hline Mesin 3 & & & menit 328 & menit 374 & menit 398 & menit 437 \\
\hline Mesin 4 & & & menit 328 & menit 374 & & \\
\hline
\end{tabular}

\section{g. Komponen Leg Flora SN Lower}

Tabel 8. Jadwal produksi komponen Leg Flora SN Lower

\begin{tabular}{|c|c|c|c|c|c|c|}
\hline \multirow{2}{*}{ Mesin ke } & \multicolumn{2}{|c|}{ Operasi ke-1 } & \multicolumn{2}{c|}{$\begin{array}{c}\text { Operasi ke-2 } \\
\text { Mesin Press 25 Ton }\end{array}$} & \multicolumn{2}{c|}{$\begin{array}{c}\text { Operasi ke-3 } \\
\text { Mesin Double Bending Press 25 Ton }\end{array}$} \\
\cline { 2 - 7 } & \begin{tabular}{c} 
Saat \\
\cline { 2 - 7 }
\end{tabular} & Suat Selesai & Saat Mulai & Saat Selesai & Saat Mulai & Saat Selesai \\
\hline Mesin 1 & menit 0 & menit 133 & menit 473 & menit 497 & menit 497 & menit 595 \\
\hline Mesin 2 & & & menit 473 & menit 497 & menit 497 & menit 497 595 \\
\hline Mesin 3 & & & menit 473 & menit 497 & m95 \\
\hline
\end{tabular}




\section{h. Komponen Leg Flora SN Upper}

Tabel 9. Jadwal produksi komponen Leg Flora SN Upper

\begin{tabular}{|c|c|c|c|c|c|c|}
\hline \multirow{2}{*}{ Mesin ke } & \multicolumn{2}{|c|}{$\begin{array}{c}\text { Operasi ke-1 } \\
\text { Mesin Double Bending }\end{array}$} & \multicolumn{2}{c|}{$\begin{array}{c}\text { Operasi ke-2 } \\
\text { Mesin Press 25 Ton }\end{array}$} & \multicolumn{2}{c|}{$\begin{array}{c}\text { Operasi ke-3 } \\
\text { Mesin Press 25 Ton }\end{array}$} \\
\cline { 2 - 7 } & $\begin{array}{c}\text { Saat } \\
\text { Mulai }\end{array}$ & Saat Selesai & Saat Mulai & Saat Selesai & Saat Mulai & Saat Selesai \\
\hline Mesin 1 & menit 113 & menit 226 & menit 595 & Menit 656 & menit 656 & menit 754 \\
\hline Mesin 2 & & & menit 595 & menit 656 & menit 656 & menit 754 \\
\hline Mesin 3 & & & menit 596 & menit 656 & menit 656 & menit 754 \\
\hline
\end{tabular}

\section{i. Komponen Back Taro}

Tabel 10. Jadwal produksi komponen Back Taro

\begin{tabular}{|c|c|c|c|c|}
\hline \multirow[b]{2}{*}{$\begin{array}{l}\text { Mesin } \\
\text { ke }\end{array}$} & \multicolumn{2}{|c|}{$\begin{array}{c}\text { Operasi ke-1 } \\
\text { Mesin CNC Bending }\end{array}$} & \multicolumn{2}{|c|}{$\begin{array}{c}\text { Operasi ke-2 } \\
\text { Mesin CNC Bending }\end{array}$} \\
\hline & $\begin{array}{l}\text { Saat } \\
\text { Mulai }\end{array}$ & $\begin{array}{c}\text { Saat } \\
\text { Selesai }\end{array}$ & $\begin{array}{l}\text { Saat } \\
\text { Mulai }\end{array}$ & $\begin{array}{c}\text { Saat } \\
\text { Selesai }\end{array}$ \\
\hline Mesin 1 & menit 179 & menit 421 & menit 421 & menit 600 \\
\hline Mesin 2 & menit 179 & menit 421 & menit 421 & menit 600 \\
\hline
\end{tabular}

\section{j. Komponen KB Flora $\mathrm{H}$}

Tabel 11. Jadwal produksi komponen KB Flora H

\begin{tabular}{|c|c|c|c|c|}
\hline \multirow{2}{*}{$\begin{array}{c}\text { Mesin } \\
\text { ke }\end{array}$} & \multicolumn{2}{|c|}{$\begin{array}{c}\text { Operasi ke-1 } \\
\text { Mesin Double } \\
\text { Shrinking }\end{array}$} & \multicolumn{2}{c|}{$\begin{array}{c}\text { Operasi ke-2 } \\
\text { Mesin Press 25 Ton }\end{array}$} \\
\cline { 2 - 5 } & $\begin{array}{c}\text { Saat } \\
\text { Mulai }\end{array}$ & $\begin{array}{c}\text { Saat } \\
\text { Selesai }\end{array}$ & $\begin{array}{c}\text { Saat } \\
\text { Mulai }\end{array}$ & $\begin{array}{c}\text { Saat } \\
\text { Selesai }\end{array}$ \\
\hline Mesin 1 & menit 0 & menit 600 & menit 754 & menit 908 \\
\hline Mesin 2 & & & menit 754 & menit 908 \\
\hline Mesin 3 & & & menit 754 & menit 908 \\
\hline
\end{tabular}

Berikut ini adalah perbandingan terhadap hasil penjadwalan perusahaan sekarang dengan penjadwalan yang diusulkan. Penjadwalan yang diusulkan adalah penjadwalan dengan menerapkan lot splitting yang di tunjukkan pada Tabel 12.

Tabel 12. Perbandingan penjadwalan sekarang dan usulan

\begin{tabular}{|c|l|c|c|c|}
\hline \multirow{2}{*}{ No } & \multirow{2}{*}{$\begin{array}{c}\text { Parameter } \\
\text { Perbandingan }\end{array}$} & $\begin{array}{c}\text { Penjadwalan } \\
\text { Sekarang }\end{array}$ & $\begin{array}{c}\text { Penjadwalan } \\
\text { Usulan }\end{array}$ & Selisih \\
\hline 1 & Makespan (menit) & 1.145 & 908 & 194 \\
\hline 2 & $\begin{array}{l}\text { Rata-rata efisiensi } \\
\text { mesin }\end{array}$ & $23 \%$ & $31 \%$ & $8 \%$ \\
\hline 3 & $\begin{array}{l}\text { Rata-rata idle time } \\
\text { (menit) }\end{array}$ & 907 & 669 & 238 \\
\hline
\end{tabular}

Berdasarkan hasil perbandingan pada tabel 12 penjadwalan usulan terbukti lebih baik dibandingkan dengan penjadwalan yang diterapkan perusahaan saat ini, karena dapat meminimumkan makespan, idle time dan peningkatan efisiensi mesin. Hal ini terlihat bahwa waktu saat selesai pengerjaan usulan lebih kecil dibandingkan dengan penjadwalan sekarang. Jika dilihat dari performansi waktu selesai pengerjaan proses produksi mempunyai efisiensi yang lebih baik dalam mengurangi waktu saat selesai pengerjaan proses produksi tersebut dalam mengurangi keterlambatan proses produksi sebesar 20,7\% jika dibandingkan dengan metode penjadwalan perusahaan.

\section{KESIMPULAN}

Ukuran performansi makespan penjadwalan usulan menghasilkan efisiensi yang lebih baik yaitu sebesar 20,7\% jika dibandingkan dengan penjadwalan perusahaan saat ini. Pada masa mendatang perlu dilakukan penelitian mengenai masalah yang sama tetapi dengan menggunakan teknik penjadwalan mundur dengan kriteria minimasi total waktu tinggal aktual sehingga dapat meminimumkan lama 
tinggal job dalam sistem sekaligus memastikan pengiriman dapat sesuai dengan saat tenggat waktu.

\section{DAFTAR PUSTAKA}

[1] Heizer dan Render. 2014. Manajemen Operasi. Jakarta: Salemba Empat

[2] Puspawardhani, Gianti dan Yusriski, Rinto. 2017. Penggunaan Aturan Prioritas Dalam Penjadwalan Perakitan dan Pemesinan Untuk Mengurangi Makespan. Prosiding Seminar Nasional IImu Pengetahuan dan Teknologi Jenderal Achmad Yani (SNIJA).

[3] Baker, K.R.1974. Introduction to Sequencing and Scheduling. Wiley \& Sons, New York.

[4] Condotta, A., Knust, S. dan Shakhlevich, N.V., 2010, Parallel Batch Scheduling of Equal Length Jobs with Release and Due Dates. J Sched, 13, 463-477.
[5] Yusriski, R., Halim, A., 2009, Penjadwalan Batch Pada Sistem Perakitan Dua Tahap Untuk Meminimasi Total Actuall Flow Time, Yogyakarta: Artikel dari APCOMS 2009: The 2nd Asia-Pasific Conference on Manufacturing System: Reconfigurable Manufacturing System for Facing Turbulent Manufacturing Environment.

[6] Low, C., Hsu, C. M., \& Huang, K. I. (2004). Benefits of lot splitting in jobshop scheduling. The International Journal of Advanced Manufacturing Technology, 24(9-10), 773-780.

[7] Baker, K.R., Trietsch, D., 2009. Principles of Sequencing And Scheduling, New Jersey: John Wiley \& Sons. 